\title{
QUESTÕES ÉTICAS E POLÍTICAS EM TORNO DA TRADUÇÃO LITERÁRIA ${ }^{1}$
}

\section{Maria Clara Castellões de Oliveira}

\section{Introdução}

No Brasil, a despeito da marcante atuação dos órgãos que congregam a classe dos tradutores e dos grandes avanços ocorridos no âmbito dos Estudos da Tradução, preponderantemente a partir da década de 1990, os leitores não-profissionais e os demais consumidores de textos traduzidos continuam sem ter ideia de um dos principais escândalos da tradução, qual seja, de acordo com Lawrence Venuti (2002), o de que essa atividade e, por analogia, o seu realizador - o tradutor - atuam como importantes formadores de identidades culturais.

Diante disso, acredito ser dever do profissional que atua na formação acadêmica de tradutores trazer à tona discussões como essas, comportando-se, dessa maneira, eticamente. Alinho-me, nesse aspecto, às posturas de Maria Tymoczko, manifestadas em "Enlargement, empowerment, ethics", capítulo que integra o livro Enlarging translation, empowering translators (2007), no qual ela disse caber a esses profissionais, aos tradutores e aos estudiosos da tradução fornecer aos que estão em processo de formação "instruções mais concretas sobre como tomar[em] decisões autorizadas e éticas na prática mais ordinária e cotidiana da tradução e sobre como continuar[em] a ser independente[s] como agente[s] ético[s]" (2007: 316). ${ }^{2}$ Em suas palavras:

\footnotetext{
Não basta [...] obrigar os tradutores a serem responsáveis, éticos ou ativistas em suas práticas, tampouco é suficiente obrigá-los a lidar de formas melhores com a tradução ou seu sentido cultural. Assim como se dá com a tradução e seu sentido cultural, questões de ética na tradução precisam ser abordadas de forma concreta e com especificidade -
}

\footnotetext{
${ }^{1}$ Versões modificadas desse artigo foram apresentadas no X Encontro Nacional de Tradutores e IV Encontro Internacional de Tradutores, organizados pela Associação Brasileira de Pesquisadores em Tradução e pela Universidade Federal de Ouro Preto, e na II Semana de Letras da Faculdade de Letras da Universidade Federal de Juiz de Fora.

${ }^{2}$ Essa e as demais traduções de Tymoczko (2007) foram realizadas por mim - [...] more concrete guidance about how to make empowered, ethical decisions in the most ordinary and daily praxis of translation, as well as how to retain one's independence as an ethical agent.
} 
uma especificidade que mais libera protocolos fixos e formulados do que os prescreve. (Tymoczko, 2007: 316)

A fim de corroborar suas alegações, Tymoczko citou, entre outros, Mona Baker, que, em texto intitulado "Translation and activism: emerging patterns of narrative community" (2006), afirmou que "tradutores e intérpretes devem ser treinados para a sociedade e não apenas para o mercado" (Baker apud Tymoczko, 2007: 320-321). ${ }^{4}$ A afirmação de Baker, de alguma forma, guarda relação com outra, de James S. Holmes, encontrada em "The name and the role of translation studies" (2001 [1972]), seminal para a compreensão das importantes mudanças que começavam a ocorrer no contexto dos estudos da tradução no início da década de 1970 e que iriam moldar o perfil da área tal como a consideramos em nossos dias. Nesse texto, Holmes, entre várias outras coisas, disse ser tarefa do especialista em tradução "fornecer conselhos competentes em torno da definição do lugar e do papel dos tradutores, do ato de traduzir e das traduções na sociedade como um todo" (2001: 182). ${ }^{5}$

A percepção de que existe um compromisso ético do tradutor para com a sociedade na qual atua encontra-se manifestada no Código de Ética do Tradutor, que, criado no âmbito da Associação Brasileira de Tradutores (ABRATES), integra os estatutos do Sindicato Nacional dos Tradutores (SINTRA). No primeiro capítulo do referido código, são listados os princípios fundamentais do tradutor, entre os quais destaco os mencionados nos parágrafos segundo e quinto, quais sejam: exercer sua atividade com consciência e dignidade, de modo a elevar o conceito de sua categoria profissional, e solidarizar-se com as iniciativas em favor dos interesses de sua categoria, ainda que não lhe tragam benefício direto. ${ }^{6}$

Isso posto, eu diria serem dois os objetivos que pretendo alcançar com o presente trabalho, um de caráter mais geral e outro de caráter mais específico, ou seja, respectivamente, apontar para o compromisso ético possuído por tradutores profissionais e por educadores e estudiosos da tradução atuantes no contexto brasileiro, e apresentar algumas estratégias de ação política conjunta para a conscientização de

\footnotetext{
${ }^{3}$ It is not enough [...] to enjoin translators to be responsible, ethical, or activist in their practices, any more than it is sufficient do enjoin them to handle cultural translation or meaning in better ways. As with cultural translation and meaning, questions of ethics in translation need to be approached in a concrete manner and with specificity - a specificity that liberates rather than prescribes fixed and formulaic protocols.

${ }^{4}[\ldots]$ translators and interpreters must be trained for society and not just for the market.

5 [...] to render informed advice to others in defining the place and role of translators, translating, and translations in society at large.

${ }^{6}$ Informações extraídas de <http://www.braziliantranslated.com/sintrape.pdf >. Acesso em 30 ago. 2009.
} 
tradutores em formação a respeito do verdadeiro poder da tradução e do tradutor. Creio que essas estratégias, uma vez postas em práticas, contribuirão para uma visibilidade maior da tradução e do tradutor por parte dos leitores não-profissionais e dos demais consumidores de traduções, os quais mencionei no início deste texto.

\section{A ética de diplomados e descolados}

Em texto publicado no número 18 (2009) da Tradução \& Comunicação: Revista Brasileira de Tradutores, vali-me, para discussão da aquisição da competência tradutória, de duas categorias em que Donald Trump, apresentador e produtor da série The Apprentice, da National Broadcasting Company (NBC), rede de televisão dos Estados Unidos da América, dividiu os profissionais que se candidataram ao cargo de seu aprendiz na terceira temporada desse programa, apresentada nos EUA em 2005 e no Brasil em 2006. A primeira categoria foi a dos candidatos que se valeram da teoria na aquisição de seus conhecimentos profissionais, a dos que tinham formação superior, os college grads, que ficaram conhecidos na versão brasileira como os "diplomados". A segunda categoria, por sua vez, foi a daqueles que se valeram da prática para construírem a sua abordagem profissional, que possuíam apenas diploma do ensino médio, os street smarts, que foram identificados na versão brasileira como os "descolados" (Oliveira, 2009a).

Nesse momento, valho-me novamente delas para discutir o quanto órgãos que reúnem diplomados e descolados avançaram no sentido de darem conta de princípios fundamentais elencados no Código de Ética dos Tradutores, mencionado anteriormente. Esclareço que incluo na categoria dos diplomados os profissionais que atuam na formação acadêmica de tradutores e aqueles que são egressos desse contexto, ao passo em que trato como descolados os tradutores que têm larga experiência profissional, mas não possuem formação acadêmica específica na área.

Pode-se dizer que existem atualmente no Brasil quatro importantes organismos que, atuando em diferentes esferas, fornecem respaldo aos tradutores: a ABRATES, o SINTRA, o Grupo de Trabalho Estudos da Tradução (GTTRAD) - até recentemente Grupo de Trabalho de Tradução — da Associação Nacional de Pós-Graduação e Pesquisa em Letras e Linguística (ANPOLL) e a Associação Brasileira dos Pesquisadores em Tradução (ABRAPT). Enquanto os dois primeiros (ABRATES e SINTRA) lidam com questões que afetam a participação do tradutor como profissional, reunindo, também, membros da categoria dos descolados, os dois últimos (GTTRAD da 
ANPOLL e ABRAPT) têm sua atenção voltada para o ensino e para a pesquisa em torno do traduzir e da tradução, congregando membros da categoria dos diplomados.

\section{1. A ABRATES e o SINTRA}

Entre as importantes ações da ABRATES, que, durante anos, foi "a única organização dos tradutores no país" (Wengorski, 2001), constam a organização da primeira tabela de preços de trabalhos de tradução e do primeiro código de ética dos tradutores, e a bem-sucedida atuação de seus representantes no reconhecimento pelo Ministério do Trabalho da profissão de tradutor, fato que se deu em setembro de 1988, ou seja, há apenas vinte e um anos. Esse reconhecimento permitiu o surgimento do SINTRA, em novembro de 1988, que, a partir de então, passou a congregar a classe dos tradutores, tendo a ABRATES e suas ações, nesse contexto, sido subsumidas por necessidades que se faziam mais prementes. No entanto, em 1999, diante da compreensão de que havia "coisas que o sindicato não podia, ou não devia fazer" (Wengorski, 2001), a ABRATES foi reativada, passando a atuar em áreas sobre as quais o SINTRA não tinha jurisdição. Em novembro de 2001, foi selada, em assembléia, a desvinculação das duas entidades.

Hoje, segundo informações contidas em sua página na Internet, a ABRATES procura "promover o desenvolvimento profissional, divulgar informações, incentivar o intercâmbio e as atividades que visam à valorização dos profissionais e da profissão", fomentando e apoiando "a realização de cursos e congressos", divulgando "oportunidades de trabalho e de desenvolvimento profissional" e incentivando o “intercâmbio entre os profissionais da tradução [...], escolas e professores, empresas de tradução e outras entidades ligadas à atividade". 7 Uma das principais atividades às quais se dedica é a aplicação de provas de credenciamento de tradutores que, de acordo com informações extraídas da Internet, "é um atestado da capacidade profissional do tradutor e um indicativo que o auxilia a apresentar-se aos clientes e colegas".

O SINTRA, por sua vez, segundo consta de sua página na Internet, tem três missões principais. A primeira delas é a busca de remuneração digna para tradutores e intérpretes, divulgando, para tanto, uma lista de preços que, segundo informa, "serve de orientação para as grandes empresas privadas e públicas pagarem os serviços de tradução que encomendam, e para os profissionais balizarem os seus preços pelo setor

\footnotetext{
${ }^{7}$ Essas e as demais informações sobre a ABRATES retiradas da Internet encontram-se disponíveis em $<$ http://www.abrates.com.br/>. Acesso em 29 de agosto de 2009.
} 
mais bem remunerado do mercado". 8 A segunda dessas missões é a luta, junto às editoras, pelo recebimento de direitos autorais por parte dos tradutores de livros. A terceira missão do SINTRA é o apoio aos tradutores nas suas questões com os clientes, oferecendo serviços advocatícios que esclarecerão sobre os primeiros passos a serem dados pelos tradutores na solução de questões.

\section{2. O GTTRAD e a ABRAPT}

O GT de Tradução da ANPOLL foi criado por sugestão do Professor Edson Rosa da Silva, da UFRJ. Sua primeira reunião se deu em 1987, no II Encontro Nacional, na UFRJ (Frota et al., 1994: 67). Desde então, os encontros do GTTRAD, ocorridos em âmbito quer regional, quer nacional, têm sido palco de discussões sobre as pesquisas realizadas na área por parte de professores universitários que, cada vez mais, ampliam o seu campo de atuação acadêmica, expandindo os estudos da tradução em direção à pósgraduação e para além das fronteiras nacionais.

A ABRAPT, por sua vez, foi criada em abril de 1992, durante o encontro do Grupo Regional de Trabalho de Tradução da ANPOLL na Universidade Estadual de Campinas (UNICAMP), concretizando um ideal que fora manifestado no ano anterior, por ocasião do encontro dos grupos de trabalho da ANPOLL, ocorrido na USP. Segundo informações encontradas na Internet, entre os objetivos da ABRAPT encontram-se os seguintes:

[...] congregar pesquisadores em tradução de todo o Brasil e promover aproximação eficiente entre os associados [...]; estabelecer canais de contato entre os associados e os responsáveis pela estrutura educacional do país e das regiões, assim como pelos órgãos ou entidades de fomento à pesquisa [...]; patrocinar a organização de conferências, cursos, jornadas, simpósios, congressos e outros eventos, assim como divulgá-los [...]; facilitar o acesso dos associados a livros, jornais, revistas e outros materiais de utilização direta ou indireta na pesquisa em tradução e das disciplinas afins ou tributárias; [...] publicar boletim informativo periódico e/ou revista que veicule a produção científica dos associados e de outros eventuais colaboradores [...]. ${ }^{9}$

Segundo Cristina Carneiro Rodrigues (2009), a criação da ABRAPT, juntamente com a produção de livros, encontros, defesas de teses e dissertações, o lançamento de revistas, contribuiu para a história de sucesso dos Estudos da Tradução no Brasil, nos a partir da década de 1990.

\footnotetext{
${ }^{8}$ Informações retiradas de $<$ http://www.sintra.org.br/site/index.php?p=c\&id=31\&codcat=19>. Acesso em 29 de agosto de 2009.

${ }^{9}$ Informações extraídas de <http://www.fflch.usp.br/sitesint/abrapt/>. Acesso em 29 de agosto de 2009.
} 


\section{Estratégias de sensibilização para questões de tradução}

Como já afirmei anteriormente, os avanços ocorridos em torno dos estudos e da prática da tradução no contexto brasileiro foram deveras significativos nos últimos 25 30 anos. No entanto, a despeito disso, os leitores não-profissionais e os demais consumidores de tradução parecem não ter adquirido ainda uma percepção da extensão do papel desempenhado pelos tradutores na formação identitária das culturas das línguas envolvidas no processo tradutório.

Diante disso, gostaria de sugerir que diplomados e descolados se unissem no sentido de construírem estratégias conscientes, consistentes e consequentes que contribuam para a sensibilização dos consumidores de tradução, desde o início de seu processo de educação, quanto a esse aspecto da atividade e do profissional da tradução. Digo isso não só em função das ações desenvolvidas até então pela ABRATES, pelo SINTRA, pelo GTTRAD e pela ABRAPT, como também por acreditar, como Tymoczko, que:

Intervenções éticas e ativistas são frequentemente muito mais eficazes e fáceis de serem realizadas em grupos - a solidariedade é geralmente mais facilitadora do que se respaldar em si mesmo sozinho na contestação de interesses poderosos e na superação de normas culturais que funcionam como uma camisa de força (Tymoczko, 2007: $322) .{ }^{10}$

Uma das estratégias possíveis, a ser implementada pelos diplomados, mais especificamente pelos que se dedicam ao ensino de tradução, está relacionada à discussão sistemática, no contexto da sala de aula, das relações de poder que envolvem a atividade tradutória e das possíveis atitudes dos tradutores em formação quando defrontados com questões relacionadas às assimetrias culturais existentes entre as línguas com as quais trabalham. A minha postura a esse respeito, como venho demonstrando em textos publicados em revistas especializadas, coaduna-se com a de Tymoczko, para quem a disciplina Estudos da Tradução "precisa tornar indagações como essas mais centrais às suas prioridades e aos seus métodos pedagógicos caso o que se queira seja um comprometimento com uma ética da diferença" (2007: 323). ${ }^{11}$

\footnotetext{
${ }^{10}$ Ethical and activist interventions are often much more effective and easier to undertake in groups solidarity is generally more enabling than relying in the self alone in contesting powerful interests and in moving beyond the straitjacket of cultural norms.

${ }^{11}[\ldots]$ must make these questions more central to its priorities and its pedagogical methods if there is to be a commitment to an ethics of difference.
} 
Tradutores formados nesse contexto terão maiores argumentos para negociarem com seus clientes — sejam eles editoras, empresas ou pessoas físicas - a inserção de notas de rodapé, glossários, explicações parentéticas, por exemplo, que deem conta dessas assimetrias culturais e, simultaneamente, insiram a marca da tradução e do tradutor no texto encomendado.

Outra atitude que considero possível de ser implementada, principalmente através da intervenção da ABRATES e do SINTRA, organizações em que são encontrados um maior número dos que venho chamando de descolados, seria a realização de gestões junto às livrarias e bibliotecas virtuais para a inserção de uma opção de busca por tradutor. Uma atitude como essa não só incitaria a comunidade leiga a se indagar sobre a importância desse tipo de profissional, como também economizaria o tempo de pesquisadores que, para os mais diversos fins, se interessam por esse tipo de informação.

Finalmente, podem — diplomados e descolados — se valer de estratégias semelhantes às utilizadas por aqueles que, com os mais diferentes tipos de objetivos e provenientes das mais diversas esferas do polissistema cultural, vêm exercendo o seu poder sobre o polissistema literário, ${ }^{12}$ contribuindo para a alteração ou a manutenção de centros e periferias. Uma delas é o compadrio, termo corrente para o que no contexto dos estudos da tradução conhecemos como patronagem (Lefevere, 1992). Nesse sentido, vale lembrar que o Conselho Federal de Enfermagem, com o propósito de fornecer maior visibilidade à classe, encomendou recentemente a escritores de renome, muitos deles imortais, a produção de livros cujos protagonistas seriam enfermeiros. Esses livros encontram-se reunidos na Coleção Anjos de Branco, organizada por Antonio Olinto, que trouxe a lume, até hoje, oito livros. ${ }^{13}$ Entre os autores que forneceram contribuição

\footnotetext{
${ }^{12}$ Utilizo o termo "polissistema" na acepção que lhe foi atribuída por Itamar Even-Zohar (1979) em "Polysystem Theory", Poetics Today, Tel Aviv, 1 (2), 287-310. Nesse texto, Even-Zohar diz entender o polissistema como "[...] um sistema múltiplo, um sistema de vários sistemas que se interseccionam uns com os outros e parcialmente se sobrepõem, utilizando ao mesmo tempo diferentes opções, ainda que funcionando como uma estrutura completa, cujos membros são interdependentes" (p. 290).

${ }_{13}$ Segundo informações disponíveis em <http://www.coren-mt.com.br/anjos_de_branco.asp > e em $<\mathrm{http}: / /$ www.corenes.com.br/interna.asp?idCliente $=102 \&$ acao $=$ materia\&id $=5239>$, acessados em $2 \mathrm{de}$ setembro de 2009, já foram publicados os seguintes títulos da referida coleção, escritos pelos seguintes autores: A dor de cada um, de Antonio Olinto; Maria da Paz, de Arnaldo Niskier; Ana Néri - a brasileira que venceu a guerra, de José Louzeiro; Guilhermina - enfermeira e tia da República, de Carlos Nejar; Histórias de aprendiz, de Moacyr Scliar; Claras manhãs de Barra Clara, de Helena Parente Cunha; Os pecados da santa, de Marcos Santarrita, e Uma luta pela vida, de Lia Persona. Aguarda-se ainda a publicação de livros dos seguintes autores, entre outros: Carlos Heitor Cony, Demócrito Jonathas Azevedo, Domício Proença e Paulo Coelho.
} 
para a coleção encontra-se Moacyr Scliar, cujo livro teve por título Histórias de aprendiz.

A propósito, Scliar é autor de um dos poucos — senão o único — texto literário brasileiro que tem por protagonista um tradutor. O conto "Notas ao pé da página", publicado em Contos reunidos (1995), compõe-se de cinco páginas em branco, cada uma delas contendo cinco notas de rodapé, redigidas por um tradutor. Essas notas, como mencionei em texto publicado recentemente,

colocam em cena as relações profissionais e pessoais de três personagens: um poeta francês; o seu tradutor que, no momento, se ocupa da tradução dos diários do mesmo, e uma mulher, identificada apenas pela inicial N., que, além de ter exercido as funções de secretária e amante do autor, acabou deixando-se seduzir pelo tradutor e com ele se casando. (Oliveira, 2009c: 83)

Elas "revelam que o autor, a despeito de ter sido traído pelo tradutor, [...] é evidentemente dependente do trabalho do mesmo" (2009b), haja vista o texto da nota de número cinco:

Note-se que, a partir desta página, $\mathrm{N}$. não é mais mencionada. $\mathrm{O}$ autor também não fala da áspera discussão que tivemos. Ofendeu-me tanto que, exasperado, anunciei-lhe que nunca mais traduziria um único verso dele. Nesse momento mudou por completo; praticamente arrojando-se a meus pés — era de uma submissão abjeta — implorou-me que continuasse sendo seu tradutor. (Scliar, 1995: 375)

De acordo com minhas próprias palavras, Scliar, tendo agido dessa forma, contribuiu, ficcionalmente, "para a desestabilização de crenças que foram desconstruídas na cena pós-moderna. Essas crenças eram a de que o original possuía uma supremacia sobre a tradução e a de que o status do autor seria superior ao do tradutor" (Oliveira, 2009b).

Talvez seja chegada a hora de diplomados e deslocados criarmos estratégias semelhantes às do que conceberam a Coleção Anjos de Branco, nos empenhando no sentido de incentivarmos — não necessariamente com a instituição de um pagamento — a produção de textos literários, dirigidos às diversas faixas etárias do público-leitor, nos quais o tradutor e a tradução sejam tematizados. Assim o fazendo, estaríamos nos valendo da ética da responsabilidade, defendida por Maquiavel e, mais tarde, por Max Weber, e que, de acordo com Renato Janine Ribeiro, no ensaio "Ética, ação política e conflitos na modernidade" (2004), "é aquela que se aplica na política ou, melhor dizendo, é aquela que vale sobretudo para quem age politicamente" (p. 66). Essa ética da responsabilidade, segundo Ribeiro, 
não é apenas a do governante. É também a do rebelde [...]. É a de todo aquele que vê o social como podendo e/ou devendo ser plasmado por uma ação criadora - e pouco importa se esta é a do indivíduo ou a do grupo. A essa ação que cria o social cabe chamar de ação política. (2004: 71)

\section{Considerações finais}

Como disse Tymoczko:

Confrontar questões relacionadas à ética, à responsabilidade e à afiliação antecede à habilidade de um tradutor se sentir autorizado - de ser ouvido, de ser visto, de ser capaz de fazer escolhas engajadas, de colocar em prática uma ampla variedade de opções de tradução, de inventar, de construir sentido, de veicular diferenças culturais, de fazer intervenções, de exercer agenciamentos ativistas de qualquer tipo (2007: 322)..$^{14}$

Assim sendo, para finalizar, eu diria que estratégias como as que mencionei - ou semelhantes a elas - necessitam ser implementadas a fim de que os consumidores de tradução adquiram uma dimensão da amplitude do papel social dessa atividade e de seu realizador. Esse é, portanto, mais um desafio político e ético que se impõe igualmente a todos os que se dedicam à tradução dentro e/ou fora da academia, ou seja, aos diplomados e aos descolados.

\section{Referências bibliográficas}

EVEN-ZOHAR, Itamar (1979) "Polysystem theory". Poetics Today 1 (2), 287-310.

FROTA, Maria Paula et al. (1994) "Um breve histórico do GT de Tradução e a sua importância para o desenvolvimento da área em nosso país". Revista da ANPOLL 1, 67-70.

HOLMES, James S. ([1972] 2000) "The name and the role of translation studies". Lawrence Venuti (org.) The translation studies reader. London, New York: Routledge.

LEFEVERE, André (1992) Translation, rewriting and the manipulation of literary fame. London, New York: Routledge.

OLIVEIRA, Maria Clara Castellões de (2009a) "A aquisição da competência tradutória ou diplomados x descolados: o que Donald Trump pode nos ensinar sobre tradução". Tradução \& Comunicação: Revista Brasileira de Tradutores 18, 2330 .

\footnotetext{
${ }^{14}$ Confronting questions related to ethics, responsibility, and affiliation is antecedent to the ability of a translator to feel empowered - to be heard, to be seen, to be able to make engaged choice, to exercise a full range of translation options, to improvise and invent, to construct meaning, to convey cultural difference, to make interventions, to exert activist agency of any sort.
} 
(2009b) "A ética do escritor, do cineasta e do tradutor na cena pósmoderna”. Verônica Lucy Coutinho Lage (org.) Literatura, crítica, cultura III. Juiz de Fora: Editora UFJF. (no prelo)

(2009c) "Cenas de E-escritura: Derrida, Freud e Moacyr Scliar". Maria Antonieta Pereira et al. Jacques Derrida: atos de leitura, literatura e democracia. Belo Horizonte: Faculdade de Letras da UFMG, Linha Editorial Tela e Texto.

RIBEIRO, Renato Janine (2004) "Ética, ação política e conflitos na modernidade". Danilo Santos de Miranda (org.) Ética e cultura. São Paulo: Perspectiva.

RODRIGUES, Cristina Carneiro (2009) "Os estudos de tradução nos programas brasileiros de pós-graduação". http://gttrad.wordpress.com/category/encontrointermediario-do-gt/. Acesso em 29 de agosto de 2009.

SCLIAR, Moacyr (1995) "Notas ao pé da página”. Moacyr Scliar. Contos reunidos. São Paulo: Companhia das Letras.

TYMOCZKO, Maria (2007) "Enlargement, empowerment, ethics". Maria Tymoczko. Enlarging translation, empowering translators. Manchester, UK; Kinderhook, USA: St. Jerome Publishing.

WENGORSKI, Paulo (2001) "ABRATES ou SINTRA? — uma abordagem histórica". http://www.abrates.com.br/abreartigo.asp?onde=ABRATES+OU+SINTRA+Um a abordagem+historica.abr. Acesso em 29 de agosto de 2009. 